\title{
Planos Diretores em Minas Gerais: vinte anos de exigência constitucional
}

\author{
Italo Itamar Caixeiro Stephan \\ Arquiteto e urbanista, professor adjunto II do Departamento \\ de Arquitetura e Urbanismo da Universidade Federal de Viçosa, \\ Universidade Federal de Viçosa, Centro de Ciências Exatas e \\ Tecnológicas, Departamento de Arquitetura e Urbanismo, AV. P. \\ H. Rolfs s/n, Campus Universitário, CEP 36571-000, Viçosa, MG, \\ Brasil, (31) 3899-1975, stephan@ufv.br
}

\begin{abstract}
Resumo
Este texto trata de uma parte da história da elaboração de planos diretores em cidades de pequeno e médio portes demográficos em Minas Gerais, a partir de 1988. Essa história tem dois períodos distintos: os primeiros doze anos, sem a regulamentação do artigo 182 da Constituição Federal e os anos seguintes, marcados pela vigência do Estatuto da Cidade. No primeiro momento, a história conta uma série de fracassos e, no segundo, recriou-se a expectativa de maior sucesso considerando os princípios do Estatuto: a função social da propriedade e a participação popular.
\end{abstract}

Palavras-chave: constituição federal e planos diretores, planos diretores participativos, planos diretores em Minas Gerais.

s origens da idéia de uma reforma urbana no Brasil remontam à década de 1960, na época do governo João Goulart (1961-1964). Durante o período da ditadura o assunto ficou abafado e só retornaria uns vinte anos após, com a abertura política iniciada durante o governo Geisel, com a constituição do principal interlocutor, o Movimento Nacional pela Reforma Urbana-MNRU, posteriormente agregando outras entidades profissionais. Nesse momento, a reforma urbana ficou enriquecida, incorporando às intervenções urbanísticas, mais preocupadas com a funcionalidade e a estética, a discussão a respeito da justiça social, que contém uma essencial dimensão espacial. O MNRU encaminhou ao Congresso, no período da Assembléia Constituinte, uma emenda popular da reforma urbana. Entretanto, o conteúdo da proposta chegou à Constituição, diluído e modificado, resumido em apenas dois artigos: o 182 e o 183. Desta forma, houve um "esvaziamento de uma amarração da reforma urbana em nível nacional", ficando as responsabilidades transferidas para os planos diretores municipais, o que resultou apenas no legalismo e tecnocracismo. A participação popular, fator chave para impulsionar a democratização do planejamento e gestão, ficou em segundo plano (SOUZA, 2002).

Nesse período de duas décadas, há duas fases da história da produção de planos diretores no Brasil: a fase pré-Estatuto e a fase do Estatuto, marcada menos pelo início de sua vigência mais pelo prazo limite de 10 de outubro de 2006.

Em 1988 entrou em vigor a Constituição Federal e a exigência de que vários municípios elaborassem seus planos diretores. Entretanto, foram necessários treze anos para que o artigo 182 fosse regulamentado, através do Estatuto da Cidade. Nessa primeira fase, o cumprimento da exigência legal ficou restrito a um pequeno número de municípios brasileiros. 


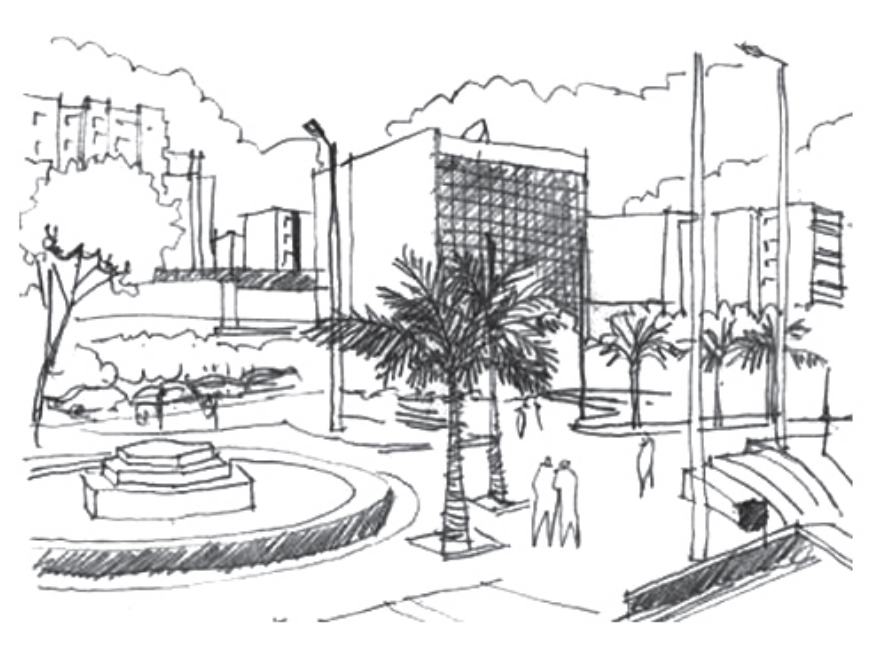

Figura 1: Varginha e Poços de Caldas. Fonte: Ilustração de Ítalo I. C. Stephan.

1 Fonte: Ministério das Cidades.

2 Pesquisa intitulada: A participação popular no processo de construção dos planos diretores participativos em Minas Gerais (2007/2008 DAU/UFV).
Em 2001, dos 1.501 municípios com mais de 20 mil habitantes, apenas 573 (38\%) tinham Plano Diretor. Cinco anos depois, mais de 562 planos diretores foram aprovados por força do Estatuto da Cidade e outros 773 estavam em processo de tramitação ou em fase de desenvolvimento' ${ }^{1}$. Em Minas Gerais, pouco mais de setenta municípios aprovaram seus planos diretores até outubro de 2006.

O panorama aqui traçado se baseou, primeiramente, no resultado de pesquisa de tese de doutorado, na qual foram estudados os dez planos diretores aprovados entre 1988 e 1998 nas cidades de médio porte demográfico em Minas Gerais (STEPHAN, 2006). A seguir, como referência para a segunda fase foi utilizado o resultado de uma pesquisa realizada como iniciação científica ${ }^{2}$, na qual foram estudados quinze planos diretores de municípios mineiros com população inferior a cem mil habitantes. Outras informações foram retiradas de resultados parciais de pesquisa, também de iniciação científica, que acompanha a implementação de planos diretores de municípios mineiros de pequeno porte demográfico, aprovados até 2006. Por último, outros subsídios vieram da experiência realizada por professores do DAU/UFV na assessoria prestada à elaboração de seis planos, entre 2002 e 2008

\section{Plano diretor e planejamento urbano}

Para vários autores (VILLAÇA, MARICATO, SOUZA, YÁZIGI) o quadro que se apresentava no final do século XX era de uma desmoralização generalizada e danosa do planejamento, especialmente dos planos diretores.

A gestão do espaço urbano ficou reduzida a um processo controlado pela classe empresarial. A administração pública assumiu posições em prol da iniciativa privada. Considerava-se vital que as cidades atraíssem investimentos para gerar novas fontes de recursos como recolhimento de tributos ou geração de empregos (OLIVEIRA, 2000). Tais demandas muitas vezes atropelaram regras urbanísticas.

O simples fato da promulgação de um plano diretor não garante sua aplicação. Qualquer cidadão comum sabe que o governo, que deveria tutelar o planejamento, é o primeiro a burlar normas, planos e leis. Além da descontinuidade administrativa, onde o governo faz e desfaz sem a menor consciência de se planejar a médio e longo prazos, o planejamento sempre esteve contaminado com dois outros problemas gravíssimos: a corrupção e o abuso da burocracia, ambos com longa história no país. A prática da corrupção se aperfeiçoou e se armou com um enorme aparato de "camuflagens de atos ilícitos", uma verdadeira arte de esconder as aparências. A corrupção é capaz até de existir mesmo com planos. Não interessa manter cabeças que pensam em formas legítimas de planejamento. Nesses casos, plano e planejamento são grandes estorvos, e nessa ótica, é melhor ficar sem eles. 
As cidades permanecem com seus administradores procurando atender as demandas urgentes criadas pela classe alta e eventualmente a média, enquanto persiste o que Francisco Oliveira (1982) identificou como "[...] desatendimento, na escala mais absurda possível das demandas das classes mais baixas". Foram poucos os méritos para os igualmente poucos municípios que acreditaram ser possível o planejamento urbano dentro do que Ermínia Maricato (1994) denominou "dramático rumo" tomado pelas cidades. A mesma autora já alertava que "nenhuma legislação, mesmo que aprovada devido a circunstâncias especiais, será implantada, do mesmo modo nenhuma lei, mesmo sendo autoaplicável garante justiça social e qualidade ambiental, pela sua simples promulgação."

Os planos só têm significado social quando legitimados. Planos legitimados são concebidos por instituições e aprovados pelo poder Legislativo que quer queira ou não, é o maior baluarte da democracia. Planos legitimados pelo Legislativo podem se tornar um incômodo para o Executivo e, por isso, foram sistematicamente engavetados. Quando o plano existe, ele pode estar servindo aos motivos mais escusos, indo desde a justificativa do empreguismo, uma forma de sustento de escritórios de consultoria, até a simples fachada de

Figura 2: Pouso Alegre e Passos. Fonte: Ilustração de Ítalo I. C. Stephan. um município possuir um plano, pois isto confere um ar de seriedade.
Nos anos de 1990 houve uma reflexão crítica em cima de uma avaliação empírica significativa, possibilitada a partir dos insucessos ligados aos problemas da aprovação de planos. Ao mesmo tempo, foi criado um amplo repertório instrumental referente à gestão democrática no processo de planejamento urbano. Mas o quadro do planejamento urbano, no período, se apresentou sem uma ancoragem normativa nas escalas supralocais, uma quase ausência de articulações entre níveis de governos e com muitos contrastes: desde a pura ausência de planejamento realizado nas prefeituras até exemplos tecnicamente dignos de nota e elogio; desde o completo desconhecimento de participação popular até esquemas ousados (SOUZA, 2002). Os municípios que elaboraram seus planos os fizeram sem apoio real das esferas superiores do Estado.

A partir do Estatuto da Cidade, a participação popular tornou-se o ponto essencial e obrigatório para a elaboração da nova geração de planos diretores, agora acrescidos do termo "participativo". Entretanto, pode-se afirmar que a participação, embora promovida de várias formas, ficou aquém do que se esperava. 0 futuro da aplicação de tantos novos planos pode estar comprometido com o pouco significativo respaldo obtido. A história dos planos diretores neste período de vinte anos poderá ser contada por uma produção de uma grande quantidade, mas provavelmente ainda com tímidos resultados qualitativos.
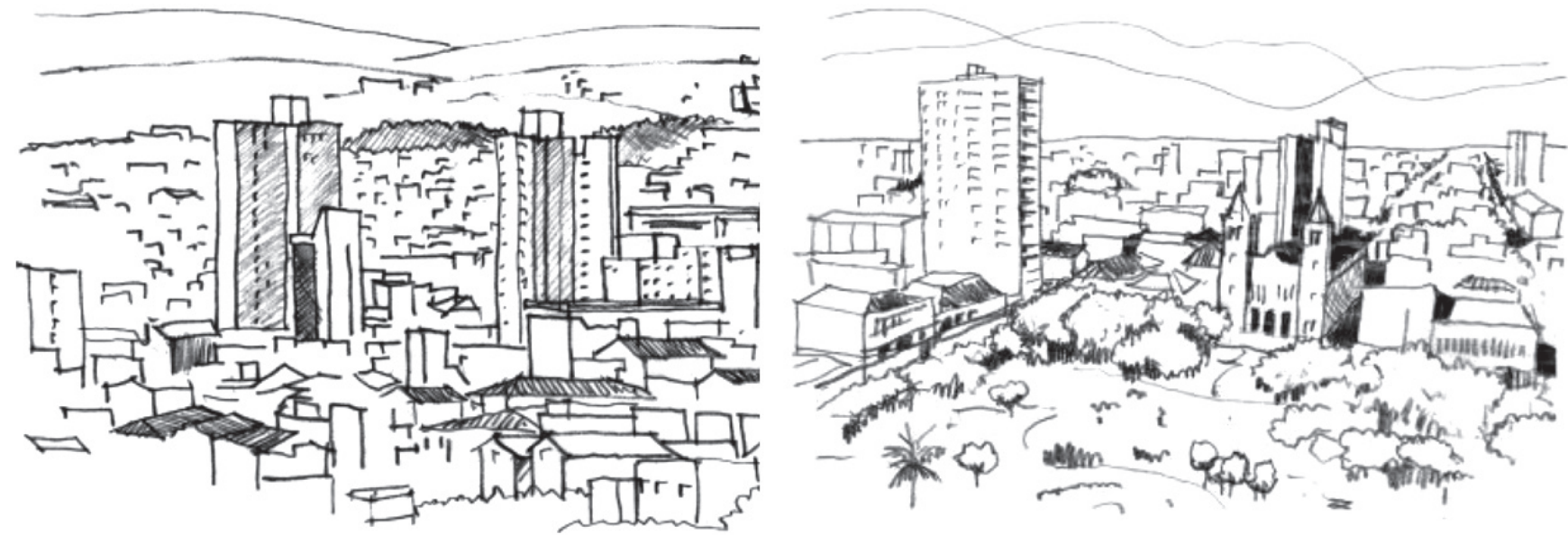

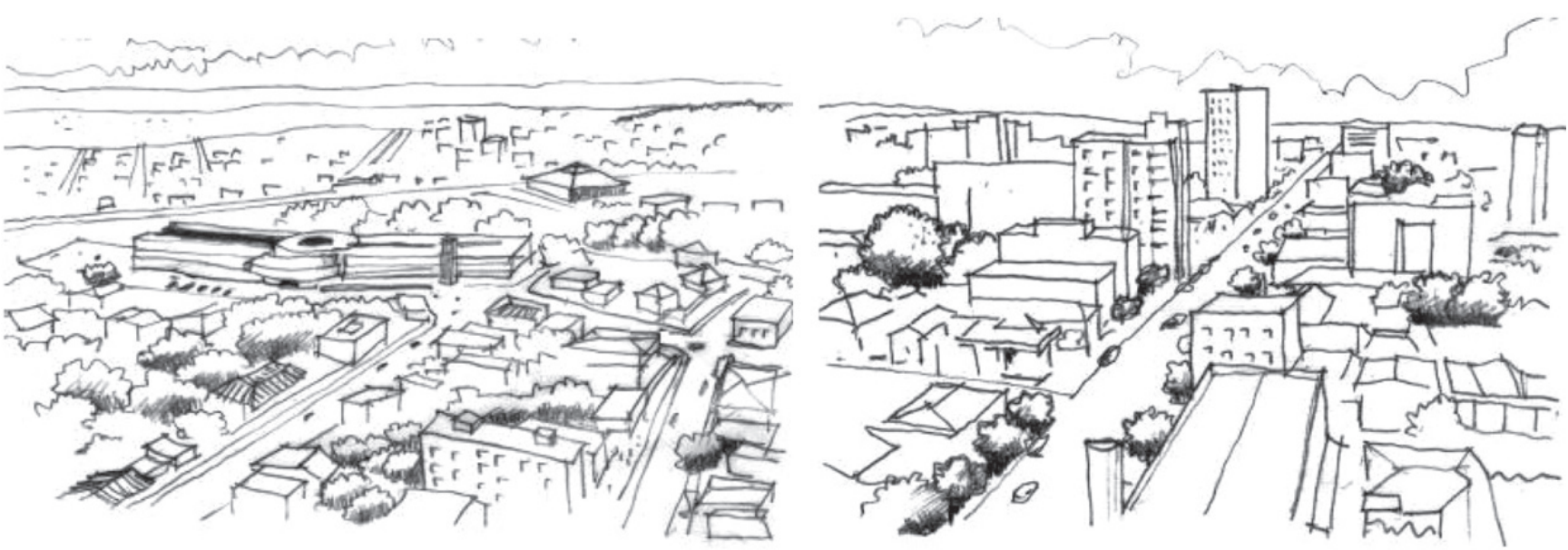

Figura 3: Betim e Patos de Minas. Fonte: Ilustração de Ítalo I. C. Stephan.

3 Conforme Boletim Informativo do Conselho Regional de Arquitetura e Engenharia - CREA/MG de julho de 2000. Os números apresentados se basearam na contagem populacional de 1995.

4 Segundo o boletim, os municípios que possuíam Plano Diretor eram: Além Paraíba, Barbacena (1962), Belo Horizonte (1996), Betim (1993), Caratinga (1996), Conselheiro Lafaiete (1999), Diamantina, Esmeraldas, Ibirité (1999), Itaúna (1986), Ituiutaba, Janaúba, João Monlevade, João Pinheiro, Frutal (1980), São Lourenço (1993), Poços de Caldas (1993), Pouso Alegre (1992), Santa Luzia (1992), Pirapora (1997), Montes Claros (1970), Ouro Branco, Ouro Preto (1996), Pará de Minas, Passos (1995), Patos de Minas (1991), Patrocínio, Sete Lagoas (1991), Três Corações (1995), Três Pontas (1988), Ubá, Uberaba (1991), Uberlândia (1994) e Varginha (1997). Há alguns planos anteriores a 1988, como Barbacena (1962), Governador Valadares (1970), Frutal (1980) e Itaúna (1986).

5 Dispositivo auto-aplicável é o dispositivo legal que, sendo completo e definido na sua formulação básica, .. continua próxima página
No final das contas, os planos diretores da primeira fase, em sua quase totalidade, como figuras centrais do planejamento urbano, não saíram do discurso, não passaram de boas intenções descoladas de implementação, não evitaram a clandestinidade, a irregularidade e a exclusão social. Nesse período, apenas algumas leis de controle do uso do solo tiveram resultados mais concretos, mas, ao atender aos interesses hegemônicos, ficaram longe de produzir cidades mais equilibradas.

\section{Planos diretores em Minas Gerais: os dez primeiros anos}

Minas Gerais, em 1991, possuía 94 cidades com mais de vinte mil habitantes, legalmente obrigadas a elaborar seus planos. Mesmo com as exigências estabelecidas nos três níveis de governo (Constituição Federal, Constituição Estadual e Leis Orgânicas Municipais), o resultado foi a inobservância por parte da maioria dos municípios. A produção de planos diretores não passou de um número muito baixo. Os órgãos públicos mineiros com atribuições de prestar assistência técnica aos municípios (Secretaria Estadual de Assuntos Municipais - SEAM e as associações microrregionais) não tiveram papel significativo na produção dos planos (STEPHAN, 2006 ).

Desde 1988, ano da aprovação da Constituição Federal, até outubro de 2001, quando entrou em vigor o Estatuto da Cidade, apenas 35 municípios tinham elaborado seus planos diretores ${ }^{3}$. Numa análise um pouco mais aprofundada desta informação, foi possível constatar algumas falhas nesse levantamento, chegando-se a um número ainda menor ${ }^{4}$.

Entre 1988 e 1998, dentre as 23 cidades mineiras com população entre 100.000 e 500.00 habitantes, apenas 10 tinham planos diretores aprovados (Vide tabela 1). Até 2001, acrescentou-se à lista Diamantina (1999) e Juiz de Fora (2001).

Na prática, os planos não passaram de conjuntos de políticas e diretrizes quase sempre inócuas e inoperantes. A maioria dos planos teve seu conteúdo limitado a políticas, objetivos, diretrizes gerais. São planos formulados quase totalmente sem dispositivos auto-aplicáveis ${ }^{5}$. Em alguns planos aparecem, eventualmente, artigos auto-aplicáveis, que tratam basicamente de instrumentos e medidas administrativas, como a criação de um conselho municipal do plano diretor. Alguns planos remeteram suas propostas para regulamentações posteriores o que, na prática, raramente se efetivou.

Poucos planos chegaram a desenvolver e explicitar os critérios para o atendimento à função social da cidade, a criar instrumentos de indução ao desenvolvimento urbano. Os instrumentos de controle do uso e ocupação do solo são poucas vezes incluídos e raras vezes na forma autoaplicável. 
continuação da nota 5 independe de normas para ser aplicado. O dispositivo autoaplicável passa a vigorar mediatamente após a vigência da lei (STEPHAN 2005, p. 162).

6 Uma forma de separar o direito de propriedade do direito de construir. Pode ser desenhado como um aumento potencial prévio acima do zoneamento em vigor para certa área da cidade, concedido de forma onerosa, ou na versão do Estatuto da Cidade, onde o solo criado é estabelecido acima de um coeficiente básico único para toda a zona urbana, ou diferenciado para áreas específicas dentro da área urbana.

7 Instrumento de regulação pública do direito de construir, onde o proprietário de imóvel urbano, privado ou público, pode ser autorizado a exercer em outro lugar ou alienar o direito de construir, desde que para fins explicitados (implantação de equipamentos urbanos e comunitários, preservação de imóvel de interesse cultural, ou para regularização fundiária, habitação de interesse social). Instrumento utilizado em Curitiba desde a década de 1960. Vide Art. 35 do Estatuto da Cidade.

8 Instrumento destinado a democratizar o sistema de tomada de decisões sobre os empreendimentos.

9 Tributo de caráter redistributivo, devido pelos proprietários beneficiados com a execução de investimentos públicos, "uma forma de ressarcimento do mais-valor criado às custas do investimento coletivo e apropriado individualmente".
Dentre os instrumentos, todos já conhecidos na década de 1990, pode-se citar o Solo Criado ${ }^{6}$, a Transferência do Direito de Construir ${ }^{7}$, o Estudo de Impacto de Vizinhança (EIV) ${ }^{8}$ e a Contribuição de Melhoria ${ }^{9}$.

Nos dez planos diretores em cidades de médio porte demográfico, em Minas Gerais (ver tabela1), pode-se delinear brevemente o que ocorreu entre 1988 e 1998. Em relação à Função Social da Propriedade, sete planos a mencionam e apenas um chegou a definir os seus objetivos e requisitos (Betim). Em relação ao sistema de planejamento urbano, pode-se observar uma ampla distância entre as intenções e sua concretização. Dos dez planos, apenas o de Pouso Alegre criou um órgão de acompanhamento do plano diretor. Quanto à criação de um conselho municipal (conselho da cidade ou do plano diretor), apenas três municípios criaram e dois os colocaram em funcionamento (Uberaba e Varginha).

Quanto à participação popular, há pouco a registrar. Apenas dois planos mencionam diretrizes sobre alguma forma de participação em decisões sobre a destinação dos recursos municipais (Poços de Caldas e Varginha). Betim e Varginha chegariam a aplicá-las nos anos de 1990. Sobre alguma forma de envolvimento da população na discussão de projetos, cinco planos mencionam e apenas um deu resultado (Betim, que teve criado um sistema de divulgação das informações e atividades da prefeitura e de discussão de projetos públicos e privados). Apenas em Betim e Poços de Caldas houve uma participação mais organizada e efetiva da população e de entidades (públicas e representativas de classes profissionais).

Sobre a presença de instrumentos de planejamento e gestão urbanos, a escassez fica explícita:

1. Edificação ou Parcelamento Compulsório e IPTU Progressivo no Tempo: sete planos previram sua aplicação, mas aguardaram a regulamentação federal e nenhum aplicou;

2. Solo Criado foi aplicado em apenas um município (Passos);

3. Transferência do Direito de Construir: três planos prevêem e apenas em um foi aplicado (Patos de Minas), mas apenas uma vez;

4. Exigência de Relatório de Impacto de Vizinhança: mencionado em apenas um plano e definido como exigência apenas no plano de Betim;

Tabela 1 - Cidades médias mineiras com planos diretores aprovados entre 1988 e 1999

\begin{tabular}{|c|c|c|c|c|c|c|c|c|}
\hline Plano Diretor / Município & 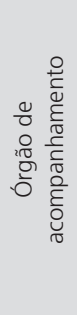 & $\begin{array}{l}\frac{0}{2} \\
\frac{0}{0} \\
\frac{0}{0} \\
0 \\
0 \\
0 \\
\frac{\varrho}{0} \\
\frac{0}{0} \\
0 \\
0\end{array}$ & 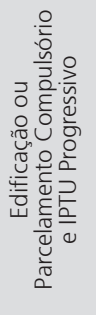 & 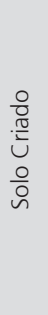 & 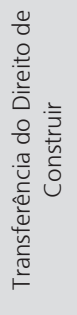 & 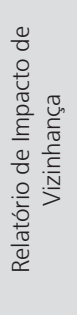 & 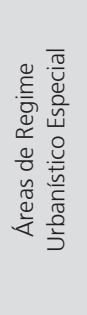 & 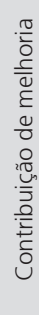 \\
\hline Betim (1993) & $\mathrm{D}$ & $\mathrm{D}$ & $\mathrm{D}$ & $x$ & $\mathrm{D}$ & $\mathrm{D}$ & A & $x$ \\
\hline Passos (1995) & $x$ & $\mathrm{D}$ & C & $A$ & $x$ & $x$ & A & $x$ \\
\hline Patos de Minas (1991) & $x$ & C & C & $x$ & $A$ & $x$ & C & $x$ \\
\hline Poços de Caldas (1996) & $x$ & $x$ & $x$ & $x$ & $x$ & $x$ & C & $x$ \\
\hline Pouso Alegre (1992) & $A$ & $x$ & $x$ & $x$ & $x$ & $x$ & $x$ & $x$ \\
\hline Santa Luzia (1992) & $x$ & $x$ & $x$ & $x$ & $x$ & $x$ & $x$ & $x$ \\
\hline Sete Lagoas (1991) & $x$ & $x$ & C & $x$ & $x$ & $x$ & C & $x$ \\
\hline Uberaba (1991) & D & $A$ & C & $x$ & $x$ & $x$ & $x$ & $x$ \\
\hline Uberlândia (1994) & D & $\mathrm{D}$ & C & C & C & X & $\mathrm{D}$ & $X$ \\
\hline Varginha (1997) & C & $A$ & C & $x$ & $x$ & C & $x$ & $x$ \\
\hline Total & 1 & 2 & 0 & 1 & 0 & 0 & 2 & 0 \\
\hline
\end{tabular}

Fonte: Tabela preparada pelo autor. 
10 Onde 36 dos 50 itens autoaplicáveis foram obedecidos (STEPHAN, 2006).

Figura 4: São Sebastião do Paraíso e Viçosa. Fonte: Ilustração de Ítalo I. C. Stephan.
5. Consórcio Imobiliário: apenas o plano de Betim define;

6. A Contribuição de Melhoria não se fez presente em nenhum dos planos;

7. Criação de áreas de Regime Urbanístico Especial (ZEIS, APP, setores especiais), em apenas dois municípios foram utilizados (Betim e Passos).

Quanto à operacionalização do sistema de planejamento urbano, o Plano Diretor apresenta dois momentos distintos: o do entusiasmo inicial de sua elaboração, concentrado basicamente apenas pela equipe técnica e alguns setores da comunidade, e o reduzido grau de implementação que se seguiu. Posto de outra forma houve, durante a elaboração dos planos, em geral, a participação de vários técnicos; amparados por um aparente apoio do Poder Executivo local, tanto na disponibilização de recursos humanos com dedicação exclusiva, quanto na destinação de recursos e equipamentos ou na contratação de consultorias. Depois de aprovados, as condições mudaram. Uma vez aprovado o plano, as consultorias foram encerradas, as equipes foram reduzidas ou divididas e passou-se a dar importância às questões mais urgentes e imediatas, como ocorreu em Poços de Caldas.

Quanto ao conteúdo, houve planos mais abrangentes (Poços de Caldas) ou mais específicos de controle do uso do solo. Os planos, tanto os muito preliminares (o simplório plano de Santa Luzia), quanto os bem elaborados, ambiciosos e detalhados (Betim e Poços de (aldas) tiveram, com exceção de Betim, destino semelhante, ou seja, um papel inexpressivo na administração municipal. Muitas das atividades e programas das prefeituras, originários de programas federais ou estaduais (relacionados a programas habitacionais, programas de saúde, educação, meio ambiente, etc.), que já estavam em andamento no período da elaboração dos planos, foram incluídos nos planos diretores. Portanto, pode-se afirmar que os planos não tiveram relação ou não exerceram nenhuma influência no sucesso ou fracasso desses programas.

A continuidade política foi fator favorável à implementação dos planos apenas em Betim, que, com três mandatos de uma mesma corrente política produziu os melhores resultados levantados ${ }^{10}$. Entretanto, em Uberaba houve uma situação similar, mas sem atenção ao plano.
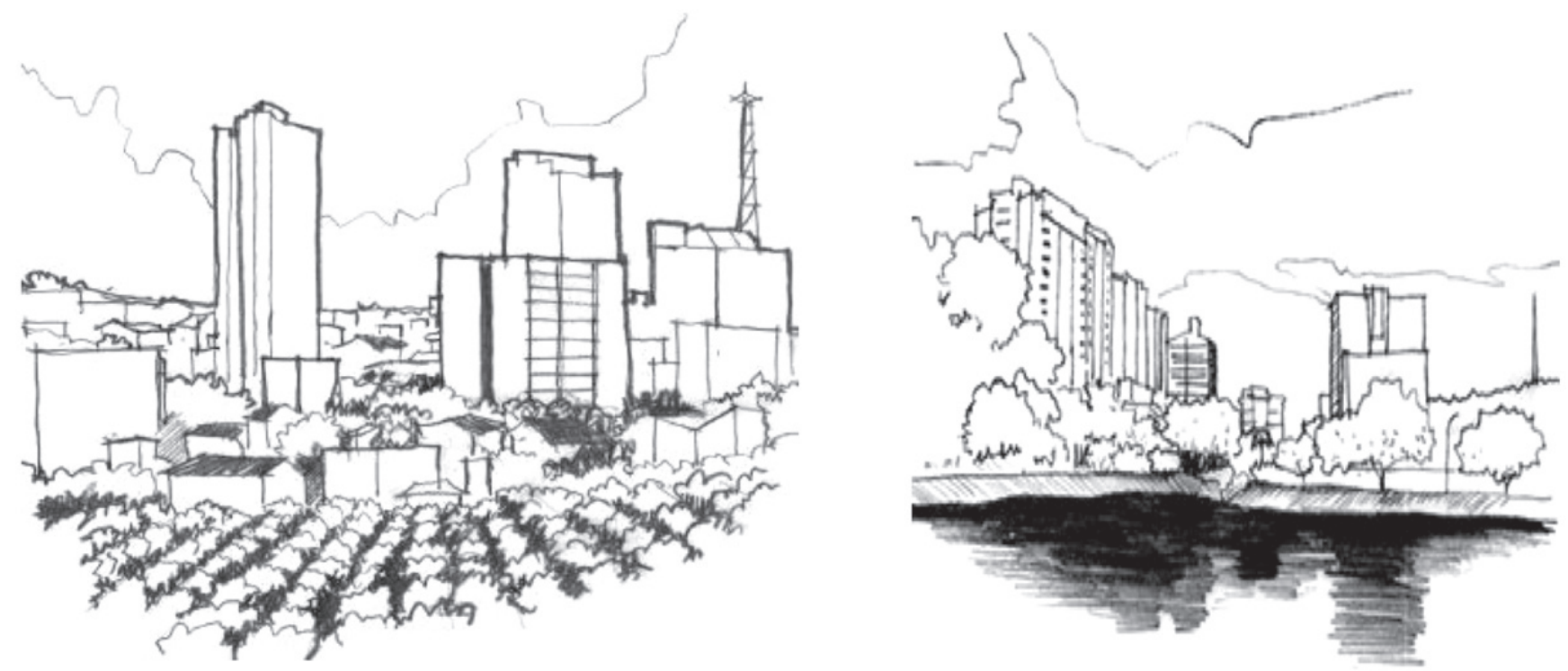


\section{A era do estatuto da cidade}

Esse período pode ser dividido em duas fases. Uma definida pelo período que se inicia com a entrada em vigor da Lei Federal 10.257, de 10 de julho de 2001 (Estatuto da Cidade) e vai até o ano de 2005, em que poucos planos diretores foram aprovados. A segunda fase se inicia no período de alguns meses antes do prazo de cinco anos (Art. 50) findo em 10 de outubro de 2006, com a correria para a elaboração da maioria dos planos.

Fase de transição: estatuto vigente e prazo de outubro de 2006

Poucos planos diretores em Minas Gerais foram aprovados entre 2001, início da vigência do Estatuto e o início de 2006, a poucos meses do prazo de 10 de outubro. Um dos primeiros a contar com os instrumentos previstos no Estatuto foi o de São Sebastião do Paraíso (LC 02/2003 de 20 de novembro). É um plano abrangente com políticas setoriais e dispositivos de controle do uso e ocupação do solo. Criou um conselho municipal de planejamento urbano (COMPAR). Para acompanhar a implementação do plano definiu como órgão de planejamento e gestão uma diretoria vinculada ao gabinete do prefeito. Dentre as dificuldades para sua elaboração, houve uma baixa participação e interesse por parte dos profissionais da construção civil ${ }^{11}$, mesmo com a existência de uma associação profissional de engenheiros e arquitetos.

Nos municípios com população inferior a cem mil habitantes, foram aprovados, dentre outros:

- Plano Diretor Estratégico de Araxá: de 2002, abrangente com políticas setoriais. Criou o Instituto de Planejamento e Desenvolvimento Sustentável, atualmente em funcionamento;

- Plano Diretor de Desenvolvimento Urbano de Unaí: de 2003, específico da política urbana e dispositivos de controle do uso e ocupação do solo. A Secretaria Municipal de Planejamento e Coordenação foi designada como órgão técnico de assessoramento ao prefeito na coordenação geral e integração administrativa das atividades de planejamento. Criou-se o
Conselho Municipal de Planejamento Urbano - COMPUR;

- Plano Diretor de Itajubá: de 2003, já contava com uma secretaria municipal de planejamento. É um plano abrangente com políticas setoriais e dispositivos de controle do uso e ocupação do solo e previu a criação de uma comissão de acompanhamento e implementação do plano;

- Plano Diretor de Itabirito: de 2005, abrangente, com políticas setoriais, com as diretrizes gerais para o zoneamento. O município já contava com uma Secretaria de Urbanismo;

- Plano Diretor Estratégico de Desenvolvimento Integrado e Sustentável de Ponte Nova: de 2003, abrangente, com políticas setoriais sem dispositivos de controle do uso e ocupação do solo. Criou a Conferência Geral do Plano, realizada de dois em dois anos, uma Comissão Técnica Administrativa, formada apenas quando da realização da Conferência e a Assessoria de Planejamento Municipal como órgão gestor do plano, que foi criada e deixou de existir.

Outros planos aprovados foram de Cláudio, São Francisco e São Joaquim de Bicas.

Em cima da hora: o prazo de outubro de 2006

A inclusão da participação popular como poder político e de cidadania aparece na Constituição Federal de 1988, que estabeleceu as bases para a democracia participativa e para a abertura de canais de participação. A participação popular foi considerada pelo Estatuto da Cidade como uma das condições básicas para a formulação dos planos diretores. Foram estabelecidos procedimentos para o processo participativo, nos quais foram incluídas: a exigência de ampla divulgação do plano, a realização das leituras técnica e participativa, o debate das propostas e formas para a realização do "casamento" entre o planejamento e a gestão urbanos. As resoluções nº. 25, de 18 de março de 2005 (Orientações quanto à forma de elaboração, implementação e execução dos Planos Diretores Municipais; e condições de obrigatoriedade de elaboração pelos municípios) e a de $n^{\circ}$. 34 , de $1^{\circ}$ de 
12 Como ocorreu no município de Buritizeiro, segundo informação do atual prefeito.

13 Cinco deles (Minduri, Cruzília, Guaxupé, Ouro Fino e a revisão do plano de Viçosa) desenvolvidos com assessoria do Departamento de Arquitetura e Urbanismo da Universidade Federal de Viçosa. Quatorze deles (e Alfenas, Areado, Botelhos, Candeias, Camacho, Campo do Meio, Congonhal, Córrego Fundo, Divisa Nova, Espírito Santo do Dourado, Fama, Ipuiúna, Poço Fundo e Serrania) desenvolvidos sob a coordenação da Associação dos Municípios do Lago de Furnas (ALAGO). Os planos de Cataguases e Lagoa Santa foram desenvolvidos com assessoria da UFMG.

14 Nesse texto entendidos com população inferior a cem mil habitantes julho de 2005 (Orientações e recomendações quanto ao conteúdo mínimo do Plano Diretor) emitidas pelo Conselho das Cidades, foram as principais referências para o desenvolvimento da metodologia de assessoramento ao processo.

O ferramental legal não definiu a profundidade e amplitude nas quais a participação popular deveria ocorrer. Instituições diferentes desenvolveram metodologias diversas para os trabalhos, permitindo que a participação transitasse nos patamares da informação, consulta e parceria (através de processos de mobilização, capacitação, reuniões públicas de consulta e debates entre as equipes técnicas e os delegados eleitos). Nos planos ficaram previstos passos futuros importantes para permitir a participação em alguns aspectos (previsão de debates e audiências públicas, orçamento participativo, conselho do plano diretor).

A movimentação em direção à produção dos planos somente ocorreu a partir de 2005, com o lançamento da campanha do plano diretor pelo Ministério das Cidades. Pode ser aventado que o desinteresse dos gestores se deu devido ao fato do término de seu mandato ocorrer em 31 de dezembro de 2004, portanto antes do prazo previsto. Uma das conseqüências desse desinteresse foi que os prefeitos que tomaram posse em $1^{\circ}$ de janeiro de 2005, além da obrigação de cumprir o prazo estabelecido - 10 de outubro de 2006 - tinham dois problemas a serem enfrentados: a inexistência de recursos para a elaboração do plano diretor e o prazo reduzido. Dessa forma, não houve um prazo ideal para o desenvolvimento de um trabalho de conscientização da necessidade e da importância da participação da população na construção do plano diretor.

Em Minas Gerais, em 2005, a Secretaria de Estado de Desenvolvimento Regional e Política Urbana, em parceria com o CREA-MG e dezenas de entidades criou um Núcleo Mobilizador de Planos Diretores. O Núcleo organizou a capacitação de cerca de mil e quinhentas lideranças de entidades da sociedade civil, agentes públicos e gestores. A idéia de elaborar planos diretores se estendeu para outros municípios não obrigados pelo Estatuto da Cidade. O secretário executivo do Núcleo, José Abílio Belo Pereira, informou que cerca de 185 planos foram iniciados (LOPES, 2005, p. 21)
O mau costume brasileiro de deixar tudo para a última hora, esperando possível adiamento do prazo, não deixou de valer para o cumprimento da exigência de aprovar os planos diretores. Muitos planos chegaram às Câmaras Municipais no fim do prazo e foram aprovados sem nenhuma discussão, sem modificações. Findo o prazo, em muitos municípios os processos ainda estavam sendo desenvolvidos.

Em Minas Gerais, nas cidades com população inferior a cem mil habitantes, dos 63 planos identificados, 7 eram anteriores a 2000 e 46 (73\%) foram aprovados entre setembro e dezembro de 2006. Outros planos foram encaminhados às respectivas câmaras municipais posteriormente ao prazo. O significativo número de planos aprovados próximo ao prazo é sinal de que muitos planos foram feitos em poucos meses e concluídos às pressas. Há sinais claros de que vários planos diretores foram feitos na base do copy and paste e mesmo assim aprovados $^{12}$

Sobre a participação popular na elaboração dos planos, houve uma variação muito grande do número de participantes. A partir da análise de vinte e um planos diretores participativos ${ }^{13}$ (vide tabela 2) de cidades de pequeno porte ${ }^{14}$, pode-se constatar que a participação foi proporcionalmente maior nas cidades menores. Baseado na experiência em Minduri e Cruzília, pode-se atribuir o fato à facilidade de fazer chegar à população o convite à participação e pela novidade do assunto. Podese observar que, em apenas 6 dos 21 municípios, a participação ficou acima de $5 \%$ do número de eleitores e, em 5 municípios, a participação ficou abaixo de $1 \%$. Tais percentuais são apenas balizas para comparação. Não há, neste trabalho pretensão de identificar o percentual ideal nem a qualidade da participação. Houve, em todos os casos, um momento em que o munícipe teve o conhecimento sobre o plano diretor e o direito de manifestar-se a respeito do destino de sua comunidade. Entretanto, pode-se estimar que há maiores chances de cobrança sobre a implementação dos planos em municípios onde 1 em cada 8 eleitores se envolveu (como nos processos de Minduri e Espírito Santo do Dourado)، do que naqueles em que a proporção foi de $1 \mathrm{em}$ 368 (Alfenas). 
Tabela 2 - Número de participantes nas reuniões públicas de coletas de opiniões para a elaboração dos Planos Diretores Participativos entre 2006 e 2008.

\begin{tabular}{|c|c|c|c|c|c|}
\hline Município & $\begin{array}{l}\text { População } \\
\text { (estimativa 2005) }\end{array}$ & $\begin{array}{l}\text { Número de eleitores } \\
\text { (estimativa 2006) }\end{array}$ & $\begin{array}{l}\text { Total de participan- } \\
\text { tes nas reuniões }\end{array}$ & $\begin{array}{l}\text { \% Número } \\
\text { eleitores }\end{array}$ & $\begin{array}{l}\text { Relação com } \\
\text { o número de } \\
\text { eleitores }\end{array}$ \\
\hline Minduri & 3.809 & 3.051 & 388 & 12,72 & $1 / 8$ \\
\hline Esp. S. Dourado & 4.235 & 3.453 & 395 & 11,44 & $1 / 9$ \\
\hline Cruzília & 15.075 & 10.672 & 687 & 6.44 & $1 / 16$ \\
\hline Congonhal & 9.748 & 6.561 & 353 & 5,38 & $1 / 19$ \\
\hline Botelhos & 15.636 & 11.947 & 655 & 5,48 & $1 / 18$ \\
\hline Córrego Fundo & 5.529 & 4.299 & 240 & 5,58 & $1 / 18$ \\
\hline Ipuiúna & 9.714 & 7.019 & 395 & 5,63 & $1 / 18$ \\
\hline Ouro Fino & 28.679 & 22.752 & 687 & 3,02 & $1 / 33$ \\
\hline Poço Fundo & 15.350 & 11.802 & 300 & 2,54 & $1 / 39$ \\
\hline Candeias & 15.499 & 11.389 & 258 & 2,26 & $1 / 44$ \\
\hline Camacho & 3.204 & 3.031 & 65 & 2,14 & $1 / 46$ \\
\hline Fama & 2.219 & 2.170 & 40 & 1,84 & $1 / 54$ \\
\hline Viçosa & 70.404 & 49.231 & 755 & 1,60 & $1 / 62$ \\
\hline Divisa Nova & 5.619 & 4.233 & 65 & 1,53 & $1 / 65$ \\
\hline Areado & 13.181 & 10.426 & 133 & 1,28 & $1 / 78$ \\
\hline Guaxupé & 47.894 & 35.187 & 388 & 1,10 & $1 / 91$ \\
\hline Serrania & 7.370 & 5.566 & 45 & 0,81 & $1 / 124$ \\
\hline Cataguases & 67.384 & 50.247 & 371 & 0,74 & $1 / 135$ \\
\hline Lagoa Santa & 44.922 & 31.430 & 190 & 0,60 & $1 / 165$ \\
\hline Campo do Meio & 11.476 & 9.137 & 45 & 0,49 & $1 / 203$ \\
\hline Alfenas & 71.628 & 50.575 & 111 & 0,22 & $1 / 455$ \\
\hline
\end{tabular}

Fonte: Tabela preparada pelo autor.

15 Situação identificada em pesquisa de iniciação científica, orientada pelo autor deste texto.

\section{Depois de aprovados}

Ao fim dos dois primeiros anos de vigência de alguns planos já é possível constatar, através de levantamentos preliminares ${ }^{15}$ que:

1. Vários planos incluíram os instrumentos de controle do uso e ocupação do solo, entretanto o restante do conteúdo permaneceu não autoaplicável e ficando dependentes de regulamentações posteriores;

2. A elaboração dos dispositivos legais e a regulamentação dos instrumentos presentes nos planos, previstos para alguns meses após a aprovação das leis dos planos, como a revisão/ elaboração de leis de controle do uso e ocupação do solo, não foi sequer iniciada;

3. A criação de conselhos (setorial de política urbana ou do plano diretor), presente em todos os planos, foi apenas iniciada, em alguns municípios, com reuniões preliminares e a indicação de prováveis nomes para a composição dos conselhos. Tais processos muitas vezes pararam logo após as primeiras reuniões;

4. A criação do órgão de acompanhamento da maioria dos planos permanece apenas no papel;

5. Em alguns planos foi prevista ampla divulgação do conteúdo, o que raramente aconteceu. Há grande dificuldade de encontrar as leis nos sites oficiais das Prefeituras e Câmaras Municipais. Portanto, os planos aprovados ficam inacessíveis ao público, restritos aos setores específicos da área de planejamento urbano e da construção civil e mais ainda desconhecidos pela maioria da população.

6. Logo após aprovados, os planos já encontraram propostas de alterações nos índices urbanísticos (coeficientes de aproveitamento em Guaxupé; ampliação da taxa de ocupação em Ouro Fino; estreitamento de vias e diminuição de áreas de lotes em Cruzília e Ouro Fino; extinção da exigência de afastamento frontal em Viçosa etc.). 


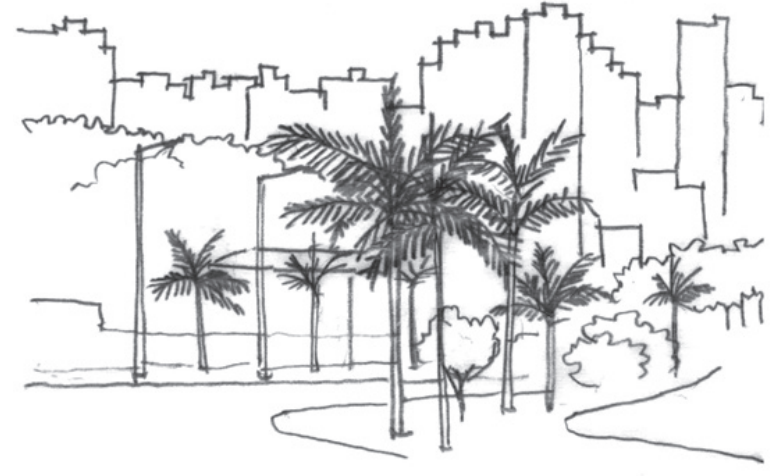

Figura 5: Uberaba e Uberlândia. Fonte: Ilustração de Ítalo I. C. Stephan.

\section{Considerações finais}

Nos primeiros dez anos os resultados positivos foram escassos, mas depois de vinte anos de exigência constitucional da elaboração dos planos diretores em Minas Gerais, houve um bom resultado quantitativo, uma vez que muitos municípios passaram a ter seus primeiros planos diretores e muitos munícipes passaram a tomar conhecimento, no mínimo que seja, sobre plano diretor e planejamento urbano. Tal conhecimento pode ser a gênese de uma fase mais favorável ao planejamento nas cidades.

A história dos planos diretores neste período de vinte anos será contada pela produção de uma grande quantidade de planos, mas com alguns resultados positivos dispersos, e parciais, dependentes de combinações políticas e do esforço e interesse de alguns. Preponderou, em muitos casos, apenas o cumprimento de uma exigência legal em elaborar e aprovar os planos, com o fantasma do posterior esquecimento.

Com todos os cuidados explicitados no Estatuto da Cidade e nas recomendações para propiciar meios adequados para garantir a participação popular na elaboração dos planos diretores, os resultados podem ser considerados tímidos. Embora tenha sido um aspecto essencial na elaboração dos novos planos diretores, pode-se afirmar que a participação ficou aquém do que se esperava. O futuro da aplicação de tantos novos planos pode estar comprometido com o pouco significativo respaldo obtido. Será valioso identificar, divulgar, apoiar e premiar os bons produtos, de forma a permitir sua disseminação e multiplicação.

Persiste a necessidade da compreensão, por parte dos dirigentes públicos municipais, do papel do planejamento urbano e para o papel da legislação urbanística. A aplicação dos instrumentos previstos no Estatuto da Cidade e presentes nos planos se reveste de dúvidas e exige disposição e coragem dos governantes. Há, principalmente nas cidades maiores, onde já existem as potenciais demandas, os desafios da regulamentação e aplicação do solo criado e do parcelamento, edificação e ocupação compulsórios e do IPTU progressivo no tempo.

Além dos desafios a serem enfrentados para mudar o quadro histórico em que uma maioria dos planos nunca saiu do papel, há os de ampliar a participação popular e fazer com que o difícil jargão técnico seja traduzido e digerido pela população. Para os municípios pouco populosos, onde não há arquiteto, nem mesmo engenheiro, onde o próprio prefeito autoriza as obras, muitas vezes inadequadas, ficarão os desafios, muito maiores que os de cidades médias, de criar e manter uma equipe técnica responsável pela implementação e o sistema de acompanhamento dos planos, ou, quem sabe, um mínimo de planejamento. Dentre os motivos alegados, um é a falta de recursos financeiros e humanos que impossibilitam incorporar o planejamento urbano, embora recursos sejam desperdiçados em gastos supérfluos e contratação de consultorias caras. Além dos planos diretores, 
os municípios passam a enfrentar as exigências de planos de saneamento básico, planos de habitação, planos de acessibilidade. As soluções passam pelo compartilhamento de equipes, por mais de um município, seja via as associações de municípios ou de consórcios.

Ao completar vinte anos de exigência constitucional, grande parte dos prefeitos terminará seus mandatos e, com isso, os planos correm mais uma vez a chance de serem esquecidos. No entanto há, além da perspectiva de cobrança pela aplicação dos planos por parte daqueles que se envolveram em sua elaboração, um aliado poderoso na figura do Ministério Público.

Entretanto, há sinais para potenciais mudanças positivas, considerando a grande quantidade de planos feitos, como o aumento das exigências para que os recursos só cheguem aos municípios via validação pelos planos e do imperativo das prefeituras na instalação de órgãos para lidar com o planejamento urbano.

\section{Referências bibliográficas}

ARAXÁ, Prefeitura Municipal de. Plano Diretor Estratégico. Lei n. 4135, de 30/12/2002.

BRASIL. Constituição da República Federativa do Brasil de 05 de outubro de 1988 .

BRASIL. Lei 10.257, de 10 de julho de 2001. Estatuto da Cidade. Brasília: Câmara dos Deputados, 2001.

CONSELHO DAS CIDADES. Resolução n. 15, de 3 de setembro de 2004. Realizar uma Campanha Nacional de Sensibilização e Mobilização visando à elaboração e a implementação dos Planos Diretores Participativos, com o objetivo de criar cidades includentes, democráticas e sustentáveis. Disponível em: <http:// cidades.gov.br/> Acesso em 03 set. 2007.

CONSELHO DAS CIDADES. Resolução $n^{\circ}$. 34, de $1^{\circ}$ julho de 2005. Emitir orientações e recomendações ao conteúdo mínimo do Plano diretor, tendo por base o Estatuto da Cidade. Disponível em: <http://cidades. gov.br/> Acesso em 03 set. 2007.

GUAXUPÉ, Prefeitura. Plano Diretor Participativo. Lei Complementar 1753/2006, de 09 de outubro de 20006

ITAJUBÁ, Prefeitura Municipal. Plano Diretor de Desenvolvimento Urbano d Itajubá. 20/02/2003.

ITABIRITO, Prefeitura Municipal. Plano Diretor de Itabirito. Lei n$^{\circ} 2466$ de 14 de dezembro de 2005.
LOPES, Geraldo. "Prefeituras perdem prazo". Estado de Minas. Belo Horizonte, 09 out. 2006, pág. 21

MARICATO, Ermínia. Brasil, Cidades: alternativas para a crise urbana. Petrópolis: Vozes, 2001.

"Reforma Urbana: Limites e Possibilidades. Uma Trajetória Incompleta". In: RIBEIRO, L. C. Q. e SANTOS JR. O. A. dos (orgs.). In: Globalização e Fragmentação e Reforma Urbana: o futuro das cidades brasileiras na crise. Rio de janeiro: Civilização Brasileira. 1994. p. 309-23.

OLIVEIRA, Francisco de. O Estado e o urbano no Brasil. Espaço e Debates n. 6, 1982, p. 35-54.

OURO FINO, Prefeitura. Plano Diretor Participativo. Ouro Fino, Ano I, ed. II, p. 2. Ouro Fino, MG. 10 ago. 2006

SANTOS, Carlos Nelson Ferreira dos. O Uso do Solo e o Município. Coleção Textos de Administração Municipal. Rio de Janeiro: IBAM, 1990, 47p.

SÃO SEBASTIÃO DO PARAÍSO, Prefeitura. Plano Diretor Participativo (LC 02/2003 de 20 de novembro).

SOUZA, Marcelo Lopes de. Mudar a cidade: uma introdução crítica ao planejamento e à gestão urbanos. Rio de Janeiro: Bertrand Brasil, 2002. 556 p.

SAULE JR., Nelson e ROLNIK, Raquel. Estatuto da Cidade - novas perspectivas para a reforma urbana. São Paulo: Polis, 2001 (Cadernos Polis 4).

STEPHAN, Ítalo I. C. A Aplicação dos Planos Diretores e Leis de Controle do Uso e Ocupação do Solo em cidades de médio porte demográfico, em Minas Gerais, no período 1988-1998. 2005. 381f. Tese (de Doutorado em Arquitetura e Urbanismo) - Faculdade de Arquitetura e Urbanismo, Universidade de São Paulo, São Paulo, 2006.

"Plano Diretor de Viçosa: avanços e limitações". Vitru vius: Arquitextos 78, Texto especial 393, nov. 2006

ARANTES, Paulo. T. L., REIS, Luiz. F., LOPES, Camila. S., FIALHO, Beatriz Campos. "Participação popular e cooperação intermunicipal: os Planos Diretores de Cruzília e Minduri, MG". Vitruvius: Arquitextos (São Paulo. Online). , v.100, p.1 - 10, 2008.

REIS, Luiz. F. "Revisão do Plano Diretor de Viçosa: participação popular e auto-aplicabilidade". Risco (São Carlos), v.6, p.84 - 93, 2008

UNAÍ, Prefeitura. Plano Diretor. Lei Complementar 44 de 25/03/2003

VILLAÇA, Flávio. "Uma contribuição para a história do planejamento urbano no Brasil". In: CSABA, Deak Schiffer, S. R. O processo de urbanização no Brasil. São Paulo: FUPAM/EDUSP, p. 169-243, 1999

As ilusões do Plano Diretor. São Paulo, edição do autor, 2005. Disponível em <www.usp.br/fau/fau/ galeria/paginas/index.html>

YÁZIGI, Eduardo. 1996. "Genética da idéia de plano no Brasil: legados políticos". In: Revista do Departamento de Geografia. São Paulo: FFLCH /USP, n. 10, abr. 1996. p. 91-103. 


\title{
Director Plans in Minas Gerais, Brazil: twenty years of constitutional exigency
}

Italo Itamar Caixeiro Stephan

\begin{abstract}
This text deals with a part of the history of the elaboration of director plans in small and medium sized cities in Minas Gerais, Brazil, since the constitutional obligation, from 1988. This history has two distinct periods: the first twelve years, without the regulation of the article 182 of the Federal Constitution, and the following years, distinguished by the validity of the City Statute. In the first period, the history tells a series of failures and in the second, revived the expectation of more success considering the Statute principles: the property social function and the public participation.
\end{abstract}

Keywords: federal constitution and director plans, participatory director plans, director plans in Minas Gerais, Brazil.

\section{Planos Directores en Minas Gerais, Brasil: veinte años de exigencia constitucional}

Italo Itamar Caixeiro Stephan

\section{Resumen}

Este texto trata de una parte da historia da elaboración de planes directores en ciudades de pequeño y medio portes demográfico en Minas Gerais, a partir de 1988. Esa historia tiene dos períodos distintos: los primeros doce años, sin la reglamentación del articulo 182 de la Constitución Federal y los años siguientes, marcados por la vigencia del Estatuto de la Ciudad. En el primer momento, a historia cuenta una serie de fracasosy, en el segundo, se recreó la expectativa de mayor éxito considerando los principios del Estatuto: la función social de la propiedad y la participación popular.

Palabras clave: la constitución federal y los planes directores, planes directores participativos, planes directores en Minas Gerais. 